\title{
Intrahepatic Bile Duct Biliary Intraepithelial Neoplasia
}

National Cancer Institute

\section{Source}

National Cancer Institute. Intrahepatic Bile Duct Biliary Intraepithelial Neoplasia. NCI

Thesaurus. Code C96943.

A neoplastic, non-invasive lesion that affects the intrahepatic bile duct epithelium. It is characterized by the presence of atypical epithelial cells with an increased nuclear/cytoplasmic ratio, nuclear hyperchromasia, and loss of nuclear polarity. 